\title{
Pemberdayaan Masyarakat Melalui Peningkatan Kesadaran Pengelolaan Sampah di Padukuhan Gunung Saren Lor
}

\author{
Reni Anggriani', Muhammad Annas ${ }^{2}$ \\ 1,2Program Studi Hukum, Fakultas Hukum, Universitas Muhammadiyah Yogyakarta \\ Email: anggriani@umy.ac.id \\ DOI: $10.18196 / p p m .31 .140$
}

\begin{abstract}
Abstrak
Dusun Gunung Saren Lor merupakan salah satu dusun yang terletak di desa Trimurti, Kecamatan Srandakan, Kabupaten Bantul, Daerah Istimewa Yogyakarta. Dusun Gunung Saren Lor memiliki kurang lebih 300 kepala kelvarga dengan rata-rata bermata pencaharian sebagai buruh. Beberapa warga bermatapencaharian sebagai pedagang dan pegawai negeri. Di dusun ini masih terdapat beberapa lahan yang kurang diperhatikan oleh pemiliknya dan masih masih terbengkalai, bahkan beberapa warga menggunakan lahan sebagai lahan pembuangan sampah. Di halaman rumah wargapun ada sampah yang berserakan, yang mengurangi keindahan rumah tersebut. Sampah yang berserakan dapat bermanfaat jika warga mempunyai pengetahuan tentang sampah, yang dapat dimanfaatkan dengan cara mengelola sampah. Tujuan dari pengabdian ini adalah tumbuhnya kesadaran untuk mengelola sampah bisa menambah penghasilan secara ekonomi. Untuk mencapai tujuan tersebut maka diadakan sosialisasi dan penyuluhan tentang sampah organik dan nonorganik supaya warga dapat mengetahui manfaat sampah yang sebelumnya dipandang tidak berguna lagi. Dengan adanya sosialisasi dan penyuluhan tentang sampah ini, warga dapat memisahkan sendiri mana sampah organik dan sampah non organik, sehingga masalah sampah dapat diselasaikan di rumah sendiri.
\end{abstract}

Kata kunci: Kesadaran masyarakat, pengelolaan sampah, Dusun Gunung Saren Lor.

\section{Pendahuluan}

Padukuhan Gunung Saren Lor secara geografis memiliki luas wilayah \pm 180.000 $\mathrm{m}^{2}$ dengan sebagian besar rumah warga ditanami dengan tumbuhan pohon jati. Wilayah yang membatasi Padukuhan Gunung Saren Lor antara lain sebagai berikut:

- Batas Utara : Padukuhan Mayongan

- Batas Barat : Padukuhan Lopati

- Batas Timur : Padukuhan Tegal Layang

- Batas Selatan : Padukuhan Gunung Saren Kidul

Dusun Gunungsaren Lor merupakan salah satu dusun di Desa Trimurti, Kecamatan Srandakan, Kabupaten Bantul, Daerah Istimewa Yogyakarta. Kondisi alam di dusun Gunungsaren Lor secara umum dapat dikatakan kurang subur karena tanahnya yang tandus dan cenderung kering dan berpasir sehingga kurang cocok untuk lahan pertanian. Oleh sebab itu sebagian besar penduduk di Dusun Gunungsaren Lor mempunyai mata pencaharian sebagai wiraswasta dengan membuka usaha sendiri dengan skala kecil dan menengah. Selain itu beberapa penduduk juga memiliki profesi sebagai pengrajin, PNS, buruh transportasi, karyawan swasta dan peternak. Pedukuhan Gunungsaren Lor memiliki jumlah penduduk sebanyak 1002 jiwa dari total 303 kepala keluarga yang terdiri atas 13 Rukun Tetangga (RT).

Permasalahan mitra di sini adalah bahwa dikarenakan wilayah yang kurang subur, mengakibatkan masyarakat banyak yang bekerja di luar rumah dengan berbagai profesi. Heterogenitas kesibukan tersebut membawa kebiasaan yang kurang baik diantaranya adalah membuang sampah rumah tangga di dekat rumah yang pada akhirnya menjadi 
tumpukan sampah yang dapat menimbulkan berbagai macam penyakit, sehingga sangat diperlukan pemahaman tentang bahaya dan manfaat sampah, karena sampah itu sendiri bila tahu jenisnya akan membawa manfaat bahkan nilai ekonomis bagi masyarakat.

\section{Metode Pelaksanaan}

Kegiatan pengabdian ini akan dilakukan sebagai berikut:

1. Sosialisasi Pengelompokkan Sampah

Program sosialisasi ini memberikan pengetahuan kepada masyarakat dusun Gunungsaren Lor agar paham macam-macam sampah, dan mengajarkan mereka untuk mengelompokkan sampah terlebih dahulu sebelum kemudian membuangnya. Mengapa sampah perlu dikelompokkan? Ini dilakukan agar sampah kemudian dapat mendatangkan nilai guna lagi setelah mereka dibuang. Misalnya, sampah dapur rumah tangga dapat dijadikan pakan ternak atau kompos; sampah kertas dapat di daur ulang menjadi kertas kembali; sampah plastik dapat dijadikan kerajinan tangan atau minimal dapat dikumpulkan dan dijual kembali.

2. Penyuluhan dilakukan:

a. Penyuluhan Pengelolaan sampah organik

b. Penyuluhan Pengelolaan Sampah anorganik

\section{Hasil dan Pembahasan}

Dewasa ini, kesibukan keseharian masyarakat dalam bekerja yang melelahkan, membuat kesadaran masyarakat akan kebersihan lingkungan semakin menurun. Sampah masih menjadi akar masalah yang belum tertuntaskan. Sampah menjadi masalah karena hanya berakhir di tempat sampah dan kemudian di tempat pembuangan akhir tanpa dikelola lebih lanjut dan akhirnya pengganggu keindahan lingkungan dan akan merusak kesehatan masyarakat, bahkan bisa mendatangkan banjir jika sampah tidak dikelola dengan baik.

Edukasi masyarakat mengenai permasalahan lingkungan yang bersifat kompleks akibat timbunan sampah diperlukan untuk membentuk kesadaran masyarakat. Faktor penyebab kepedulian lingkungan didasari cara berpikir dan perilaku manusia. Partisipasi aktif warga menjadi hal yang penting untuk diidentifikasikan dalam aksi pengelolaan sampah. Upaya menjaga kelestarian lingkungan harus bermula dari diri individu dengan memulai dengan melakukan hal-hal kecil. Perubahan yang dilakukan kemudian dapat 'ditularkan' menjadi kebiasaan dalam keluarga ataupun masyarakat, sehingga terjadi perubahan besar. (Asteria, 2016)

Di Pedukuhan Gunung Saren Lor, sampah merupakan permasalahan yang harus diselesaikan. Penumpukan sampah yang diakibatkan dari sampah rumah tangga, pada akhirnya akan menimbulkan masalah baru, yang akan menimbulkan banyak penyakit yang berdampak juga pada warga sekitar. Untuk membantu mengatasi hal tersebut, maka Program KKN PPM ini mengangkat tema Kesadaran Masyarakat dalam Pengelolaan Sampah di Pedukuhan Gunung Saren Lor, dengan harapan akan memberikan edukasi dan sosialisasi bagaimana untuk dapat mengetahui jenis sampah yang pada akhirnya dapat membedakan jenis-jenis sampah, dengan cara memberikan 
sosialisasi dan penyuluhan tentang sampah dan jenisnya, karena disinilah pentingnya pemahaman akan pengelolaan sampah untuk kehidupan. Pengadian ini bertujuan untuk menyadarkan masyarakat akan pentingnya pengelolaan sampah dan mengubah pola pikir masyarakat bahwa sampah tak hanya sekedar sampah, namun juga bisa menghasilkan nilai ekonomis.

Pelaksanaan pengabdian ini dilaksanakan pada tanggal 20 Januari 2020 dengan dihadiri oleh 50 peserta yang berasal dari warga Dasa Wisma Pedukuhan Gunung Saren Lor, Desa Trimurti, Kecamatan Srandakan, Kabupaten Bantul. Pada pelaksanaan program ini menghadirkan narasumber yaitu Ibu Meitia Dwi Selfiani yang merupakan anggota dari BUMDes Trimurti.

Sosialisasi dan penyuluhan yang disampaikan oleh narasumber yaitu tentang bagaimana dapat mengelola sampah dengan baik yang pada akhirnya akan membawa nilai ekonomis bagi warga.
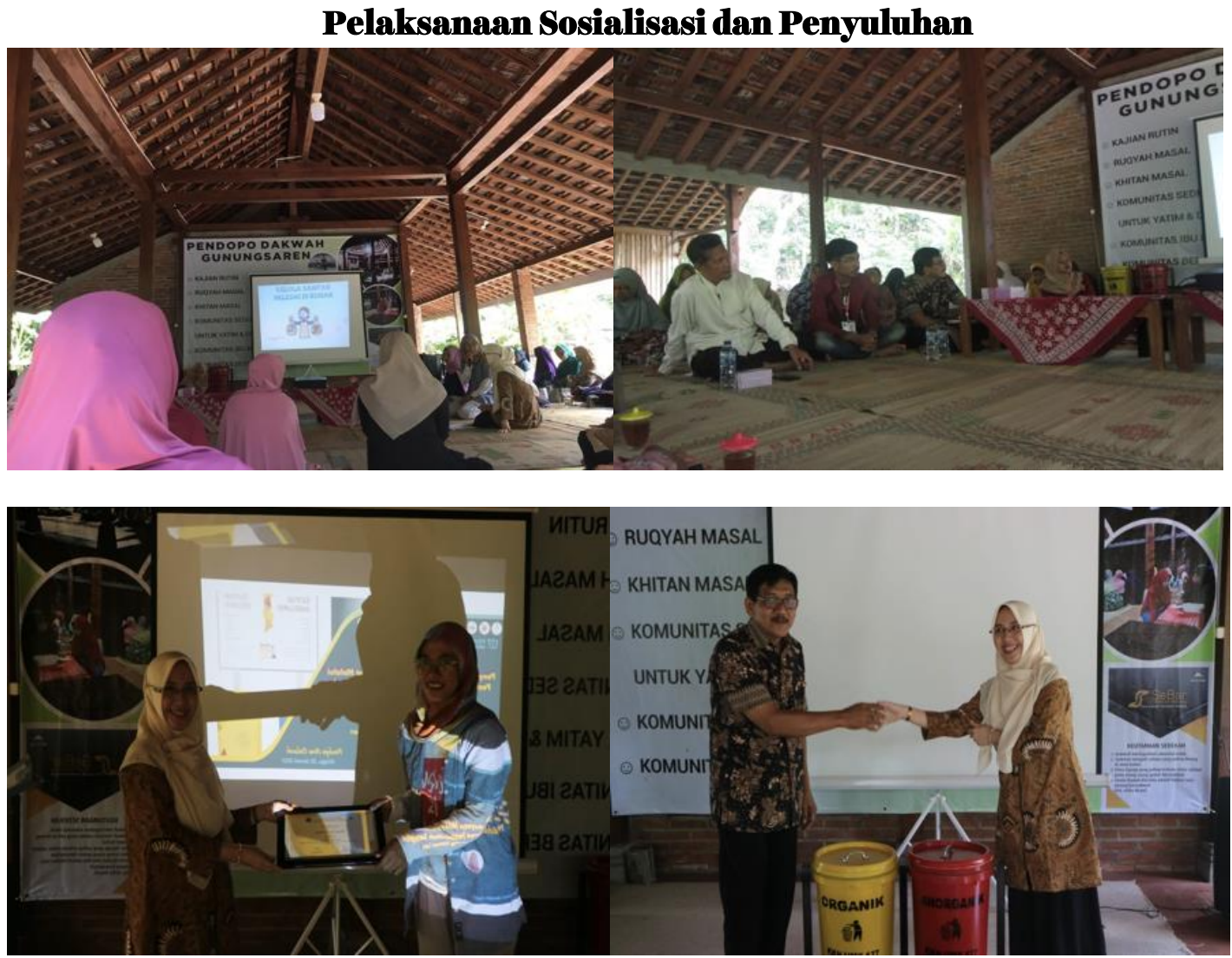


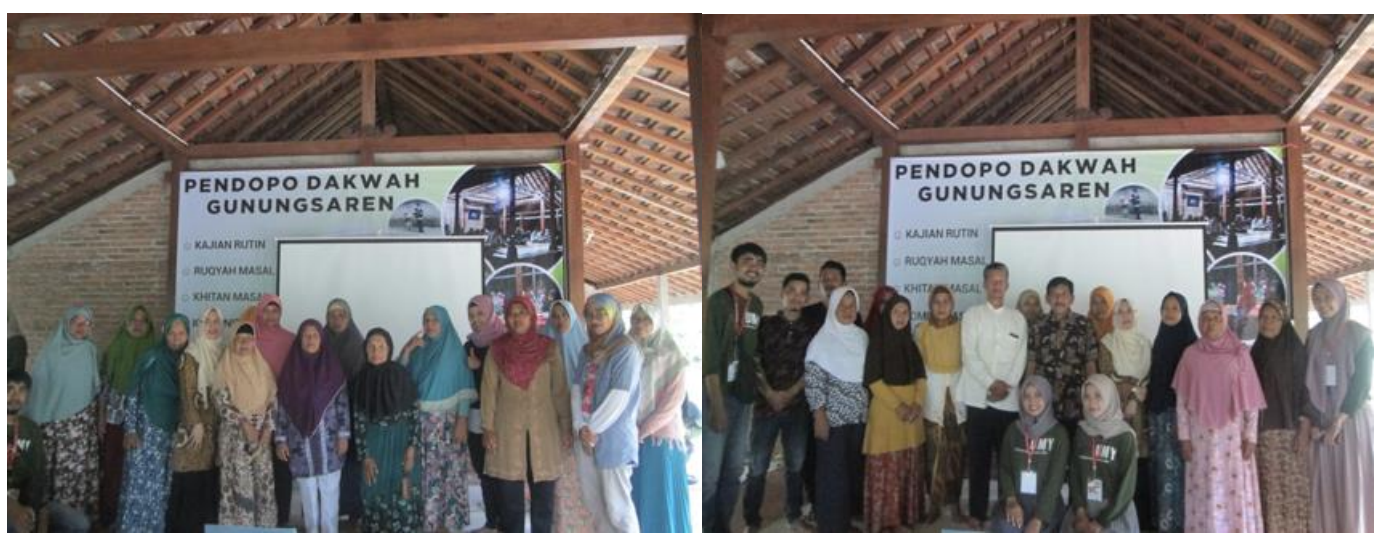

Filosofi mendasar mengenai pengelolaan sampah sesuai dengan ketetapan dalam Undang Undang Nomor 18 Tahun 2008 tentang Pengelolaan Sampah, sekarang perlu ada perubahan cara pandang warga terhadap sampah dan cara memperlakukan atau mengelola sampah. Cara pandang masyarakat pada sampah seharusnya tidak lagi memandang sampah sebagai hasil buangan yang tidak berguna.

Sampah sekarang harus dipandang sebagai sesuatu yang mempunyai nilai guna dan manfaat. Dalam rangka melaksanakan Peraturan Pemerintah No. 81 Tahun 2012 tentang Pengelolaan Sampah Rumah Tangga dan Sampah Sejenis Sampah Rumah Tangga, maka praktik mengolah dan memanfaatkan sampah harus menjadi langkah nyata dalam mengelola sampah.

Sekarang warga harus meninggalkan pandangan lama yang membuang sampah begitu saja diganti dengan cara mendidik dan membiasakan masyarakat memilah, memilih, dan menghargai sampah yang dapat mengembangkan ekonomi kerakyatan melalui pengembangan bank sampah (Trina, E., Tallei, T.E., Iskandar, J., Runtuwene, S., dan Filho, 2013) yang berhasil guna dan dapat meningkatkan perekonomian warga.

Pemilahan sampah rumah tangga yang termasuk kategori sampah organik dapat dijadikan kompos sedangkan sampah rumah tangga anargonik ditabungkan ke bank sampah untuk didaur ulang kembali dan dapat dijadikan bahan yang bernilai ekonomis (Jumar, Fitriyah, N.,dan Kalalinggie, 2014) dan menurut Singhirunnusorn dkk (Singhirunnusorn, W., Donlakorn, K., dan Kaewhanin, 2012), perubahan cara berpikir masyarakat mengenai pengelolaan sampah rumah tangga untuk mengurangi sampah di sumber melalui partisipasi warga harus diintegrasikan ke dalam proyek bank sampah yang berbasis masyarakat.

Pengelolaan sampah rumah tangga berbasis komunitas juga diperlukan dikarenakan sumber sampah domestik perlu dikelola secara mandiri (Riswan, Sunoko, 2011), oleh para warga. Pengetahuan, sikap dan keterampilan warga mengelola sampah rumah tangga untuk melakukan daur ulang juga menjadi hal penting dalam pengelolaan sampah (Akhtar, H.,dan Soetjipto, 2014), yang sangat diharapkan dari warga Padukuhan Gunung Saren Lor setelah mendapatkan pengetahuan tentang tata cara pemisahan dan pengelolaan sampah berdasarkan jenisnya. Bank sampah di Desa Trimurti telah didirikan oleh BUMDes yang telah berjalan beberpa tahun yang lalu, dengan cara menyambut bola yaitu mengambil kepada warga yang belum bisa mengelola sampahnya. sehingga bagi warga yang kesulitan dan kerepotan untuk 
mengelolanya bisa menghubungi bank sampah, supaya sampah yang ada tersebut dapat dikelola dengan baik dan bermanfaat.

\section{Simpulan}

Kesadaran masyarakat terhadap pengelolaan sampah yang baik, dapat dilaksanakan dengan jika mempunyai pengetahuan sampah dan jenisnya yaitu sampah organik atau anorganik karena dengan mengetahui jenis sampah sehingga akan memudahkan dalam mengelolanya. Sampah organik dapat dipakai sebagai pupuk cair, dan sampah anorganik dapat dikelola menjadi barang kerajinan sehingga dapat meningkatkan perekonomian rumah tangga. Pelaksanaan penyuluhan dan sosialisasi pengelolaan sampah telah meningkatkan pemahaman dan pengetahuan warga tentang bagaimana cara mengelola sampah. Sampah yang tadinya dibuang secara sembarangan atau dibakar, dengan penyuluhan ini warga menjadi paham bagaimana cara mengelola sampah dengan baik, dan membakar sampah akan membuat polusi udara yang membahayakan bagi lingkungan. Penyuluhan dan sosialisasi pengelolaan sampah ini dapat membantu mencapai moto bahwa sampah selesai di rumah.

\section{Ucapan Terima Kasih}

1. Lembaga Penelitian, Publikasi, dan Pengabdian Masyarakat Universitas Muhammadiyah Yogyakarta (LP3M UMY)

2. Kepala Desa Trimurti, Kecamatan Srandakan, Kabupaten Bantul.

3. Kepala Dukuh Gunung Saren Lor Bapak Suwardi

4. Warga Pedukuhan Gunung Saren lor.

5. Mahasiswa KKN kelompok 127

6. Pihak terkait yang tidak bisa disebutkan satu persatu.

\section{Daftar Pustaka}

Akhtar, H.,dan Soetjipto, H. (2014). Peran Sikap dalam Memediasi Pengaruh Pengetahuan Terhadap Perilaku Minimisasi Sampah Pada Masyarakat Terban, Yogyakarta. Jurnal Manusia Dan Lingkungan, 9(1), 31-38.

Donna Asteria, H. H. (2016). Bank Sampah Sebagai Alternatif Strategi Pengelolaan Sampah Berbasis Masyarakat Di Tasikmalaya. Jurnal Manusia Dan Lingkungan, 23(1), 136-141.

Jumar, Fitriyah, N.,dan Kalalinggie, R. (2014). Strategi Pengelolaan Sampah Rumah Tangga di Kelurahan Lok Bahu Kecamatan Sungai Kunjang Kota Samarinda. Journal Administrative Reform, 2 (1), 771-782.

Riswan, Sunoko, H. R. da. H. (2011). Pengelolaan Sampah Rumah Tangga di Kecamatan Daha Selatan. Jurnal Ilmu Lingkungan, 9(1), 31-38.

Singhirunnusorn, W., Donlakorn, K.,dan Kaewhanin, W. (2012). Household Recycling Behaviours and Attitudes toward Waste Bank Project. Journal of Asia Behavioural Studies, 2(6), 35-47.

Trina, E., Tallei, T.E., Iskandar, J., Runtuwene, S., dan Filho, W. . (2013). Local Community-based Initiatives of Waste Management Activities on BunakenIsland in North Sulawesi, Indonesia. Research Journal of Environmental and EarthSciences, 5(12), 737-743. 